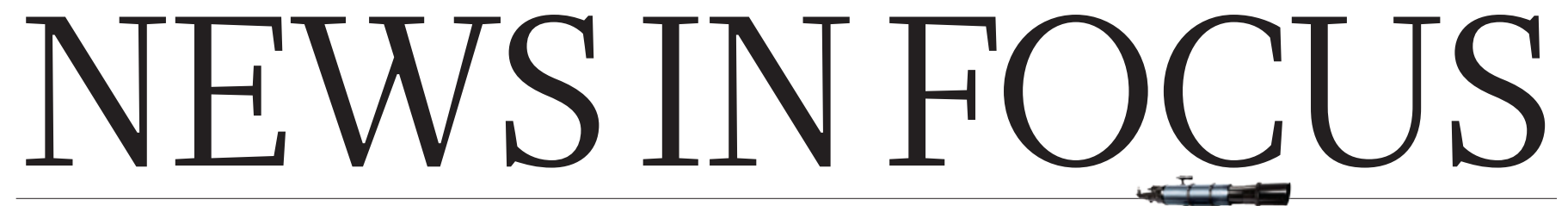

CLIMATOLogy Climate scientists attempt to lure talented physicists $\mathbf{p} .140$
BIOTECHNOLOGY Synthetic biologists write the rules for living machines p.141
AFRICAN SCIENCE Regional hub will provide research autonomy p.142

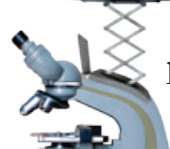

CAREERS What the future holds for a growing postdoc population $\mathbf{p . 1 4 4}$

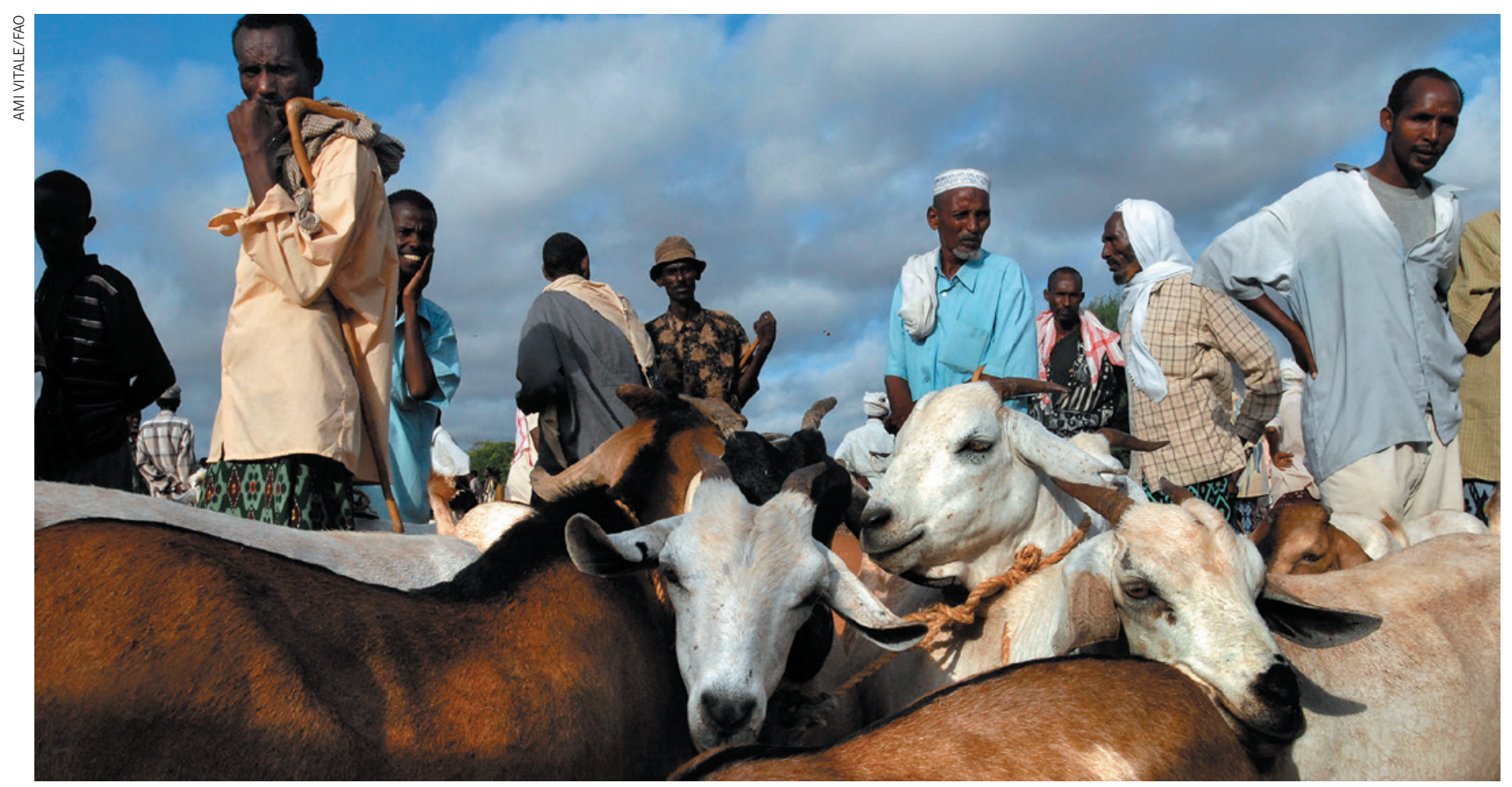

Goats and sheep are sold frequently, which could challenge the vaccination effort against peste des petits ruminants.

\title{
Race to stamp out animal plague begins
}

\section{Killer disease that is scourge of world's poorest ruminant farmers is ripe for elimination.}

BY EWEN CALLAWAY

$\mathrm{H}$ umanity wiped out smallpox in 1980 and the cattle virus rinderpest in 2011. Polio stands on the brink of eradication, with just 21 cases recorded this year worldwide. Now, health officials have launched a global effort to vanquish yet another disease - a sheep- and goat-killer that is little known in rich countries, but creates economic ruin for the world's poorest people.

A conference hosted by the United Nations in Abidjan, Côte d'Ivoire, from 31 March to 2 April, marked the roll out of a global campaign to eradicate by 2030 the sheep and goat virus, which is known as PPR - an abbreviation of its French name, peste des petits ruminants. PPR eradication is technically feasible, say animalhealth specialists, but it is uncertain where the effort's organization and billions of dollars of necessary funding will come from.

"This is an exercise in persuading the world community and funders that this work could and should be done," says Jeffrey Mariner, an epidemiologist at Tufts University veterinary school in North Grafton, Massachusetts, who attended the meeting.

PPR is related to measles and rinderpest, which once threatened the livelihoods of cattle herders, especially those in Africa. Causing high fever, diarrhoea and lesions in the mouths of sheep and goats, PPR is highly infectious and kills $30-70 \%$ of the animals it infects. It is endemic across northern, central and west Africa and south Asia, and it has more recently taken hold in China and Turkey.

The UN puts the economic costs of PPR at between US $\$ 1.5$ billion and $\$ 2.1$ billion per year, a burden borne by some of the world's poorest people, who rely on sheep and goats for food and income (see 'Cost of a goatkiller'). "Sheep and goats are the cattle of 
- the poor, and they are the bank for the poor," says Bernard Vallat, director-general of World Organisation for Animal Health (OIE) in Paris, which co-hosted the meeting.

"Somebody in Kenya said to me, "if the goats die, the children don't go to school'," says Michael Baron, a virologist at the Pirbright Institute in Woking, UK. Sheep and goat herding also helps many women in the developing world to attain self-sufficiency.

PPR ticks many of the boxes needed for an eradication campaign: an effective vaccine has been available for decades, and scientists have created formulations that remain effective for weeks without refrigeration. Diagnostic tools, including some that can be used in animal pens, are accurate. There also seems to be no wild reservoir from which the virus may rebound once wiped out from domestic flocks and herds. "It's one of those no-brainers," says Christopher Oura, a veterinary virologist at the University of the West Indies in St Augustine, Trinidad, who studies PPR. "The tools are out there to eradicate the virus."

A cost-benefit analysis by Mariner and his colleagues estimated that eradication will save more than $\$ 42$ billion over a hundred years. The fresh success of the rinderpest eradication campaign also gives many hope that a second animal disease can be eliminated for good. "Before everybody forgets that, people want to get the rest of the world on board," says Baron.

PPR eradication presents its own challenges. The campaign strategy focuses on dramatically

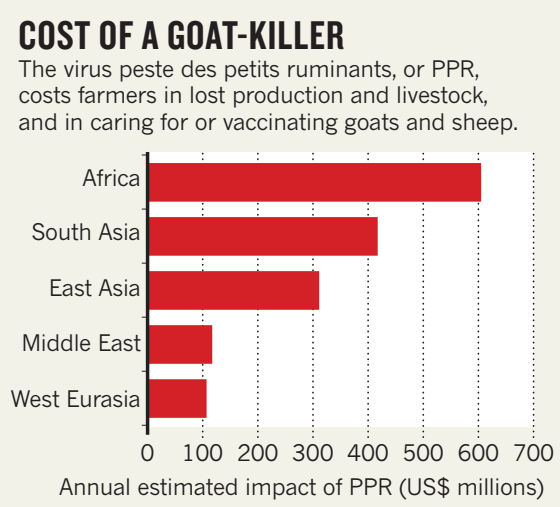

ramping up and coordinating vaccinations, but this is complicated because sheep and goats are more abundant than cattle in most of the developing world, and people hold onto them for a shorter time before selling or slaughtering them. The campaign will also attempt to systematically target areas where the virus is spreading, but veterinary services are weak in many of those regions.

One positive effect of the campaign will be the construction of veterinary infrastructure in these areas. This will have impacts beyond PPR, for example by helping to combat other small ruminant diseases, such as goat and sheep pox. "There should be good knock-on effects for poor people," says Baron.

How exactly the eradication effort will be coordinated has yet to be hashed out. The UN Food and Agriculture Organization, which co-organized the Abidjan meeting, and the OIE are looking for Western governments, non-governmental organizations and charities to foot much of the estimated cost of $\$ 7.6$ billion to $\$ 9.1$ billion.

Samuel Thevasagayam, deputy director for livestock at the Bill \& Melinda Gates Foundation in Seattle, Washington, which has contributed funds to PPR vaccine efforts in the past, says that the organization is evaluating whether to support the campaign. "It's a huge commitment - that's what causes donors to think carefully," says Mariner. He hopes that the management structure that emerges will be nimble and open to new ideas and approaches. "With PPR, we're going to have to continue to innovate," he says. -

CLIMATE SCIENCE

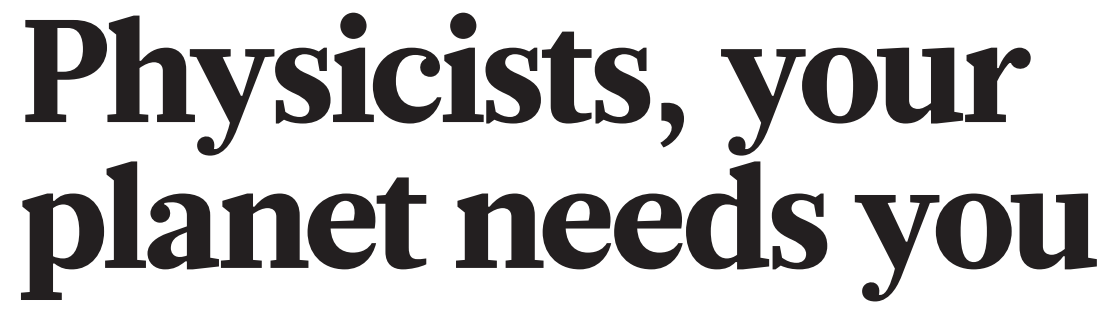

\section{Climatologists highlight cloud mysteries in an attempt to lure physicists to their field.}

\section{BY QUIRIN SCHIERMEIER}

$\longrightarrow$ limate science needs more mathematicians and physicists. So say prominent climatologists who are trying to spark enthusiasm for their field in budding researchers who might otherwise choose astrophysics or cosmology. Talented physical scientists are needed to help resolve mysteries that are crucial to modelling the climate - and, potentially, saving the planet - the group says, such as the ways in which clouds are formed.

There is a misconception that the major challenges in physical climate science are settled. "That's absolutely not true," says Sandrine Bony, a climate researcher at the Laboratory of Dynamic Meteorology in Paris. "In fact, essential physical aspects of climate change are poorly understood."
To attract physics and mathematics students to the speciality, Bony and her collaborators have presented some of the field's grand challenges in magazines such as Physics Today (B. Stevens and S. Bony Phys. Today http://doi. org/3f9; 2013), and are organizing summer schools for students from an array of scientific backgrounds.

Last week in Nature Geoscience, Bony's team outlined four of the field's deepest questions, including how clouds and climate interact and how the position of tropical rain belts and midlatitude storm tracks might change in a warming world (S. Bony et al. Nature Geosci. http:// doi.org/3gb; 2015). The questions are best tackled, says Bony, by creating more realistic climate simulations - an approach that she hopes will appeal to physicists.

The perception that climate science is 'solved' is an inadvertent result of pressure on climatologists to convey a simple message to the public - for instance, that all dry regions will get dryer and all wet regions wetter in a warming climate, says Piers Forster, a climate modeller at the University of Leeds, UK. That has made the science "sound somewhat dull", he says.

"We too quickly turn to the policy implications of our work and forget the basic science," adds Bjorn Stevens, a director at the Max Planck Institute for Meteorology in Hamburg, Germany, and a co-author of the Nature Geoscience paper. Although climate scientists agree on the basics - for example, climate change is primarily the result of human activity - large uncertainties persist in 'climate sensitivity', the increase in average global temperature caused by a given rise in the concentration of carbon dioxide.

As Bony and co-authors argue, understanding how the warming climate might affect cloud cover, which influences the amount of sunlight reflected back into space and thus Earth's energy cycle, is key to addressing these uncertainties. A major weakness of current climate models is their limited ability to simulate the convection by which humid air is lifted into the atmosphere and which drives cloud formation and rainfall. In some instances, the models cannot even agree on whether the future will bring more rain or less.

Building better cloud-resolving models requires enormous computer power, as well as people who have a deep understanding of 